\title{
Comparison of hyperemotionality caused by lesions in the septal and ventromedial hypothalamic areas in the rat ${ }^{1}$
}

\author{
DEVENDRA SINGH, North Dakota State \\ University, Fargo, N. Dak. 85102
}

Rats with bilateral lesions in the septal and ventromedial hypothalamic nuclei were compared for emotionality rating under two conditions. In one condition rats were handled every day, while in the other condition, they were not handled until 3 weeks after surgery. In both handled and nonhandled situations, septal-lesioned rats show attenuation of hyperemotionality, while ventromedial-lesioned rats show no such attenuation. The lack of attenuation of hyperemotionatity in ventromedial-lesioned rats probably reflects an important integrative role played by this area in emotional behavior.

The electrophysiological work of Kaada (1960, 1962) suggests that the septal and ventromedial hypothalamic (VMH) areas both may be involved in an inhibitory system which modulates motor responses in an intact animal. Thus, hyperemotionality which has been reported after the destruction of either the septal (e.g., Brady \& Nauta, 1953; King, 1958; King, 1959) or VMH (Hetherington \& Ranson, 1942; Green, 1967) area can be considered a release phenomenon, consequent on the removal of inhibitory impulses. If septal lesions and VMH lesions reflect the disorder of the same central mechanism, it will be instructive to compare the hyperemotionality produced by these types of lesions.

There are many studies which have isolated characteristics of septal hyperemotionality; for example, on the basis of daily rating on the King scale, it was reported that septal hyperemotionality subsides within 6 or 7 days (King, 1959). Yutzey et al (1964) not only confirmed this finding but also reported that septal rats show a spontaneous attenuation of emotionality if not handled or rated for 21 days postoperatively. However, there have been no systematic studies regarding VMH emotionality except informal observations stating these animals "... seem to be hyperemotional indefinitely."2

The purpose of the present investigation was twofold: first, to obtain a comparison of ratings between septal and VMH rats in the different situations of the King scale; and second, to investigate whether or not VMH animals will show spontaneous attenuation in emotionality similar to septal rats over a period of time.

\section{PROCEDURE}

The Ss were 60 female Holtzman albino rats, 99-1 10 days old at the beginning of the experiment. All Ss were individually caged under constant lighting and ventilation conditions and were given ad lib food and water throughout the experiment. All Ss were rated by two independent raters on the emotionality scale, excluding the category of urination and defecation, for 7 consecutive days before surgery. Surgery was done under Nembutal sodium anesthesia. Lesions were stereotaxically placed in accordance with the König and Klippel rat brain atlas (1963) and were made by direct current electrocoagulation. Thirty Ss received bilateral lesions in the septal area, while the remaining $30 \mathrm{Ss}$ received bilateral lesions in the VMH area. Six VMH and four septal Ss were lost in surgery. Twenty-four hours after surgery, the first postoperative emotionality ratings were obtained. After these ratings, half of the Ss (12 VMH and 13 septal) from each lesion condition were randomly assigned to the "nonhandled" group. These Ss were never touched or their cages moved for 3 weeks after which period these Ss were rated for 5 consecutive days. The remaining $12 \mathrm{VMH}$ and 13 septal Ss were rated daily for a total of 8 days and were thus considered the "handled" group. A final rating was obtained on the 45 th postoperative day for both handled and nonhandled groups.

The Pearson correlation coefficients between the rating scores and between the two raters for all days of rating were significantly high and positive (I's ranging between .89 and .93), indicating good interrater reliability.

At the completion of the experiment, all Ss were perfused with $10 \%$ formalin, and their brains were removed and embedded in paraffin. Sections in the lesioned areas were cut at 6-micron thickness and stained in Hemotoxylin and Eosin ( $\mathrm{H} \& \mathrm{E})$. Brains were reconstructed to determine the locus and extent of lesions.

\section{RESULTS}

The histological analysis showed that all lesions were generally comparable for both handled and nonhandled groups. All lesions intended in septal region were large and resulted in bilateral damage to all septal nuclei and consistently invaded the ventriculus lateralis. All Ss also had bilateral damage to the tractus diagonalis (Broca) and fornix precommissuralis. Some $\mathrm{Ss}(\mathrm{N}=11)$ had partial damage to the tractus striohypo-

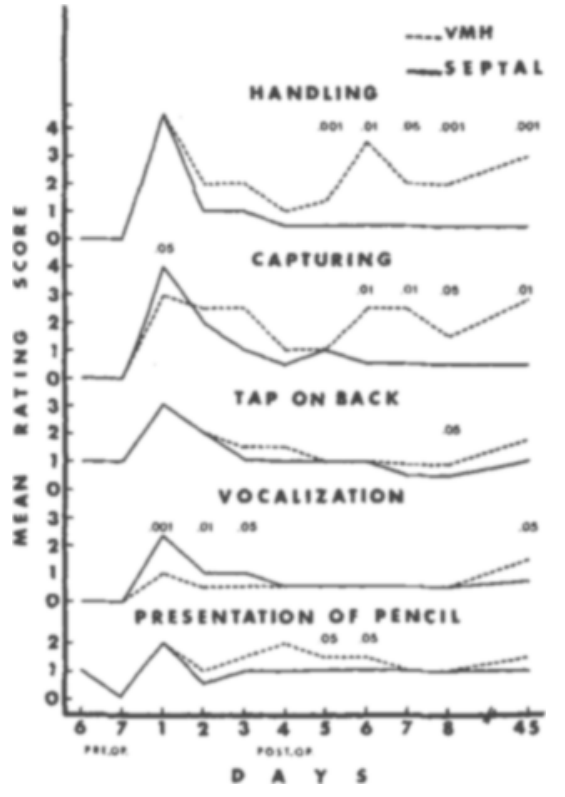

Fig. 1. Mean emotionality scores for handled septal and VMH lesioned rats under each category of rating scale. The numerical values within the figure represent the probability values for each of the differences shown to be significant by the two-tailed t test.

thalamicus. The anterior-posterior extent of the lesions was somewhat larger spreading between A 8620 to 7890 levels of the Konig and Klippel rat atlas.

All VMH lesions were well placed, spreading between A 4620 to 4230 levels of the König and Klippel atlas. Lesions consistently caused total bilateral damage to ventromedial nuclei though the lesions were more laterally spread than intended. Four Ss had partial damage to the nucleus dorsomedialis.

\section{Handled Group}

Figure 1 compares the mean rating scores of septal and VMH animals under the different categories of the emotionality scale over days of rating. The figure also depicts the probability values for those days only on which the difference between the two groups was significant (two-tailed $t$ test). As evident from the figure, septal animals started with equal or higher scores than the VMH animals in every category and, as would be expected on the basis of previous studies (King, 1959; Yutzey et al, 1964), showed a very rapid decline in each category over days of testing. 


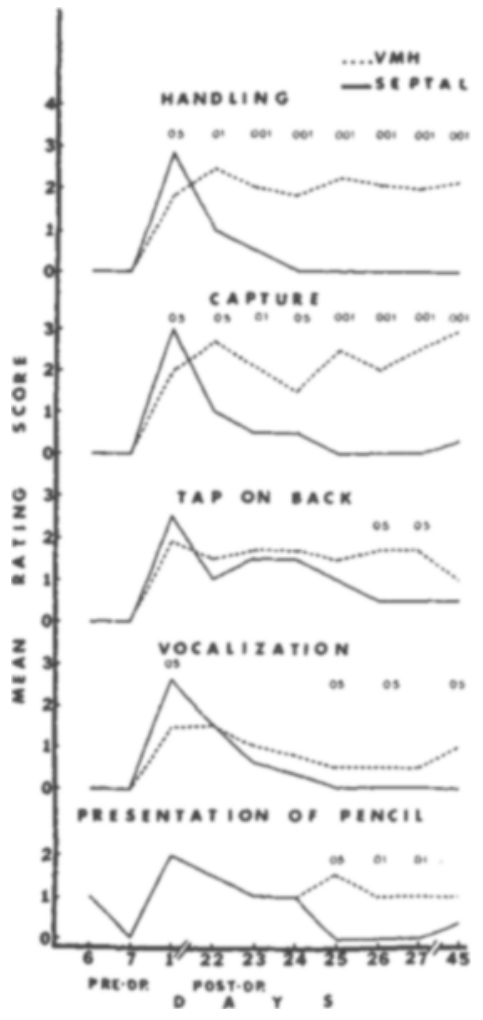

Fig. 2. Mean emotionality score for nonhandled septal and VMH lesioned rats under each category of rating scale. The numerical values within the figure represent the probability for each of the differences shown to be significant by the two-tailed $t$ test.

VMH animals presented a very different picture. They maintained higher scores than the septal Ss from the second day of rating onward, except in the category of vocalization. This trend was evident particularly in the handling and capturing categories, while in the other categories the scores tended to become similar by the fourth or fifth day of rating. The difference in scores between VMH and septal animals with regard to the capturing and handling categories can be attributed to the high values assigned within these categories to biting behavior. Septal animals rarely bit after 3.5 days of rating whereas VMH animals engaged in excessive biting which did not show a reduction over time.

Unlike VMH animals, septal animals seemed to overreact to sudden and jerky movements of any objects within the cage. Also, at least for the first 2 days of rating, the "response to tap on the back" or "startle" response by septal animals was quite different from that of the VMH animals. Practically all septal animals jumped out of the cage while being tested for this category, whereas such an exaggerated response was very rarely observed in any VMH animal.

\section{Nonhandled Group}

Figure 2 shows the mean emotionality rating of septal and VMH animals for four periods: 2 days before surgery; $24 \mathrm{~h}$ after surgery; 6 days after the 3-week no-handling period; and on the 45 th day after surgery. Again, as in the handled group, all of the septal animals scored equal to or higher than VMH animals on the first rating. A comparison of the ratings after the 24-h postoperative period and on the first day after 3 weeks of no-handling in septal animals revealed a great attenuation in emotionality, a finding consistent with that of Yutzey et al (1964). VMH animals showed hardly any spontaneous attenuation in emotionality in the no-handling period, if only the total scores (ignoring categories) are considered. However, an inspection of the categories showed that VMH animals maintained higher scores in the categories of capturing and handling, while their behavior in other categories did show some spontaneous attenuation. This trend is very similar to that of the handled group. The behavior within each category for both septal and VMH animals was identical to the handled group when later days of rating were compared for both of the groups.

The findings regarding septal emotionality and its attenuation over a period of time are consistent with previous findings (King, 1959; Yutzey et al, 1964). Similarly, the fact that all VMH Ss became obese by the 45th postoperative day is consistent with previous studies (Hetherington \& Ranson, 1942; Teitelbaum, 1964).

\section{DISCUSSION}

In conclusion, the hyperemotionality caused by a VMH lesion differs from septal hyperemotionality on two counts: first, VMH animals retain a greater degree of emotionality in spite of daily handling; and second, VMH animals do not show spontaneous attenuation in emotionality over the period of testing as septal animals do.

Thus, it seems that the somatomotor inhibitory pathway, which includes both septal and VMH areas (Kaada, 1960), is involved in restraining emotionality in normal animals. Hence, when a neural component within this inhibitory pathway is destroyed, a "release" of emotional behavior is observed. Within this framework, the reported hyperreactivity of VMH. lesioned rats to eletrical shock (Turner, Sechzer, \& Liebelt, 1967) can be explained by referring to the removal of inhibitory influences.

However, the question of why the destruction of one neural component produces a "release" phenomenon and its consequent attenuation while the destruction of another component within the same system does not, can be answered only by assuming that one component plays a more important role in the observed behavior than another. Thus, the retention of hyperemotionality of VMH-lesioned animals over a period of time could be due to the fact that "inhibitory influences of 'rhinencephalic' structures on savage behavior are ultimately channeled through this hypothalamic area ..." and "... this hypothalamic area appears to be a nodal point for a number of fiber systems, chiefly from anterior 'thinencephalic' areas, concerned with the regulation of autonomic functions and with inhibitory influences on somatomotor activities [Kaada, 1962] ."

\section{REFERENCES}

BRADY, J. V., \& NAUTA, W. J. H. Subcortical mechanisms in emotional behavior: Affective changes following septal forebrain lesions in the albino rat. Joumal of Comparative \& Physiological Psychology, 1953, 46, 339-346.

GREEN, P. C. Effects of early vs late lesions on cognitive-affective behavior in rats: VMH. Psychonomic Science, 1967, 7, 11-12.

HETHERINGTON, A. W., \& RANSON, S. W. The spontaneous activity and food intake of rats with hypothalamic lesions. American Journal of Physiology, 1942, 136, 609-617.

KAADA, B. R. Cingulate, posterior orbital, anterior insular and temporal pole cortex. In $J$. Field, H. W. Magoun and V. E. Hall (Eds.), Handbook of physiology. American Physiological Society, 1960, 2, 1345-1372.

KAADA, B. R., RASMUSSEN, E. W., \& KVEIM, $O$. Impaired acquisition of passive avoidance behavior by subcallosal, septal hypothalamic and insular lesions in rats. Journal of Comparative \& Physiological Psy chology, 1962, 51,661-670.

KENNEDY, G. C. The role of depot fat in the hypothalamic control of food intake in the rat. Proceedings of the Royal Society, (London), 1952, B, 578-592.

KING, F. A. Effect of septal and amygdaloid lesions on emotional behavior and conditional avoidance response in the rat. Joumal of Nervous \& Mental Disease, 1958, 126, 57-63.

KING, F. A. Relationship of the 'septal sy ndrome' to genetic differences in emotionality in the rat. Psychological Reports, 1959, 5, 11-17.

KÖNIG, J. F, R., \& KLIPPEL, R. A. The rat brain: $A$ stereotaxic attas. Baltimore: Williams \& Wilkins, 1963.

TURNER, S.G., SECHZER, J. A., \& LIEBELT, R. A. Sensitivity to electrical shock after ventromedial hypothalamic lesions. Experimental Neurology, 1967, 19, 236-244.

YUTZEY, D. A., MEYER, P.M., \& MEYER, D. R. Emotionality changes following septal and neocortical ablations. Journal of Comparative \& Physiological Psychology, 1964, 58, 463-465. NOTES

1. The present experiment was partly supported by Research Grant MH13418-01 from the National Institute of Mental Health.

2. Teitelbaum, P. Personal communication, 1964. 